\title{
Bibliometric Structured Review of Mobile Information Systems
}

\author{
Sunday Adewale Olaleye ${ }^{1}$, Ismaila Temitayo Sanusi ${ }^{2}$, and Oluwaseun \\ Alexander Dada ${ }^{3}$ \\ ${ }^{1}$ University of Oulu, Oulu, Finland; sunday.olaleye@oulu.fi \\ ${ }^{2}$ University of Eastern Finland, Joensuu, Finland; ismails@uef.fi \\ ${ }^{3}$ University of Helsinki, Helsinki, Finland; alexander.dada@ helsinki.fi

\begin{abstract}
This study attempts to fill the identified research gap in the existing literature through a bibliometric analysis and discovered 20 highly global citedpapers with 1376 citations and yielded eight (8) core categories of knowledge in MobIS: (1) Information Systems, (2) Adoption, (3) Acceptance, (4) Satisfaction, (5) Information Systems Success and (6) Information Systems continuance. The results show that the distribution of the annual papers flows along the downslope. It was a bit stable in 2016 and since then descend from 2017 to 2020. As a young discipline, there is a need for more productivity, impact, and collaboration in the field of MobIS.
\end{abstract}

Keywords: Mobile Information Systems, Bibliometric, Structured Review, mobIS

\section{$1 \quad$ Introduction}

Mobile information systems (MobIS) is a growing trend in the industry because of its potential to enhance the business processes and performance. Ubiquitous (MobIS) allows interaction of mobile devices and other systems with impact on the society, economy, governance, education, commerce, healthcare [1], and industry [2]. The (MobIS) has been extremely useful during the ongoing pandemic (COVID-19). For instance, recent study of Drew [3] reported the rapid implementation of mobile technology for real-time epidemiology of COVID-19. According to the authors this realtime information systems has potential to showcase data on predictive symptoms, risk factors, clinical outcomes, and geographical hotspots and so far, has generated above 2.8 million users. The use of (MobIS) is relevant in different fields and in academia its research is ongoing because (MobIS) is an evolving discipline.

This study discovered a gap in the study of Shiau, Yan \& Lin [4] and this study intend to fill this gap and expand the work of [4]. For instance, the intellectual structure composition of (MobIS) is subject to change from time-to-time and [4] extracted data from the Web of Science from 1996-2015 and this study follow up their study by extracting data from the Web of Science from 2016-2020. Due to the gap in the existing literature, this study proposed the following research questions: (1) Why is im- 
portant to explore the trend of the core knowledge and the intellectual structure of the MobIS in detail? Why is TCCM framework relevant to the discipline of MobIS?

MobIS is diffusing across the continents and a recent study investigates the use of interaction design patterns in Brazil with focus on government mobile information systems and discovered that in Brazil, the government's mobile information systems is at the low level of employing the interaction design patterns. This paper could be a panacea for the Brazilian to use governmental services in mobile systems efficiently [5]. Further, Saeed \& Xu, [6] extended the Bass model to information system-based services and discovered the effect of dis-adoption and re-adoption in innovation diffusion process. Besides, [7] proposed a MobIS framework for Bangladeshi ready-made garments (RMG) and showcase the relevance of MobIS for empowerment process. The study of He, Nazir \& Hussain, [8] emphasised the importance of literature review and mentioned that it will help to understand the researchers and other academic stakeholder's productivity levels, relevant theories and methods that works best in different situations.

The introduction to MobIS precedes the synopsis of MobIS, then followed by methodology section and results section. Also, with discussion, conclusion and finally, the recommendations for the future research.

\section{Synopsis of Mobile Information Systems}

Combination of mobile technology and information systems evolved as the discipline of mobile information systems. Mobile technology use and advancement is expanding globally and contributes to the ubiquitous of information systems. Information systems has metamorphized over years from traditional record keeping to the present cloud storage system. Mobile information systems is an "information systems in which access to information resources and services is gained through end-user terminals that are easily movable in space, operable no matter what the location, and, typically, provided with wireless connection" [9]. This definition indicate accessibility, technology, operability, and connectivity. MobIS will continue to be relevant to the academic community and the industry because it can provide future new value-added services in different context of use [9]. MobIS addresses a wider user group and pose new challenges such as privacy, users' orientation, poor quality of network connection and use high distraction. Model-based approach and Task-Technology Fit was proposed for the development of MobIS [10] [11]. A recent study also contribute to the literature of MobIS and explored the key content of the MobIS field and identified the intellectual structure of MobIS [4]. The existing studies motivates this bibliometric review and TCCM analysis.

\section{Synopsis of Mobile Information Systems}

There are different types of literature review, approaches, techniques, and tools (He, et al. 2021) [8]. The earlier studies have employed the traditional method and software to explain different kinds of phenomenon in conjunction with academic commu- 
nity productivity. One of such review is bibliometric method. Bibliometric method focus on bibliographic data analysis based on published literature to give insights of the body of knowledge for a specific or combined field of inquiry [12] [13]. This study adopts bibliometric method to explain the phenomenon of mobile information systems. The study utilised relevant literature from leading global database (ISI Web of Knowledge database) and extracted 1074 from 2016-2020 with 37814 references, 3980 author's keywords (Table 1) with the following search query: ((Abstract-TitleKeyword ("mobile information systems"). The total collected data was 1132 and after language exclusion (Portuguese -12 , Spanish -9 , Russian -3 and Turkish -3 ), the English outlet accounts for 1100 and the inclusion of articles and conference proceedings yield 1074. A full record information from Web of Science database with focus on bibliographical information, citation information, abstract, keywords and other relevant information was exported in BibTeX file format. Because of the limitation of 500 dataset per download, the study employed Texmaker (a free cross-platform latex editor) to merge the files. This study utilised bibliometrix R package (R studio) for the data analysis because of its dynamic statistical algorithm and integrated data visualization features [14]. The study combined the bibliometric and TCCM framework to get a better understanding of mobile information systems impact.

Table 1. Demographic Information

\begin{tabular}{ll}
\hline Description & Result \\
\hline Main Information Data & $2016-2020$ \\
\hline Timespan & 682 \\
Sources (Journals, Books, and others) & 1074 \\
Documents & 3.18 \\
Average years from publication & 5.101 \\
Average citations per documents & 1.183 \\
Average citations per year per doc & 37814 \\
References & \\
DOCUMENT TYPES & 674 \\
Article & 28 \\
article; early access & 6 \\
article; proceedings paper & 366 \\
proceedings paper & \\
DOCUMENT CONTENTS & 1671 \\
Keywords Plus & 3980 \\
Author's Keywords & \\
AUTHORS & 3221 \\
Authors & 3609 \\
Author Appearances & 87 \\
Authors of single-authored documents &
\end{tabular}




\section{AUTHORS COLLABORATION}

Single-authored documents $\quad 95$

Documents per Author $\quad 0.333$

Authors per Document 3

Co-Authors per Documents $\quad 3.36$

Collaboration Index $\quad 3.2$

\section{$4 \quad$ Analysis}

\subsection{Trends of MobIS Research}

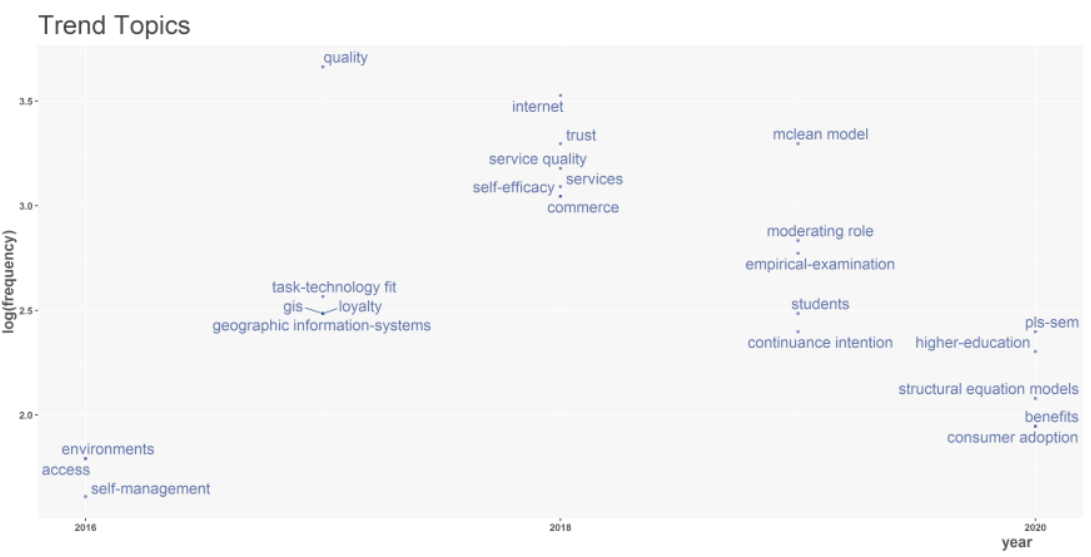

Fig. 1. Trends Topic in MobIS research

Shown in fig. 1 are trend topics in MobIS research. Among the top 24 most trend topics, quality has the highest frequency followed closely by internet and trust. The least trending topic is self-management. 


\subsection{Yearly Articles vs Citation}

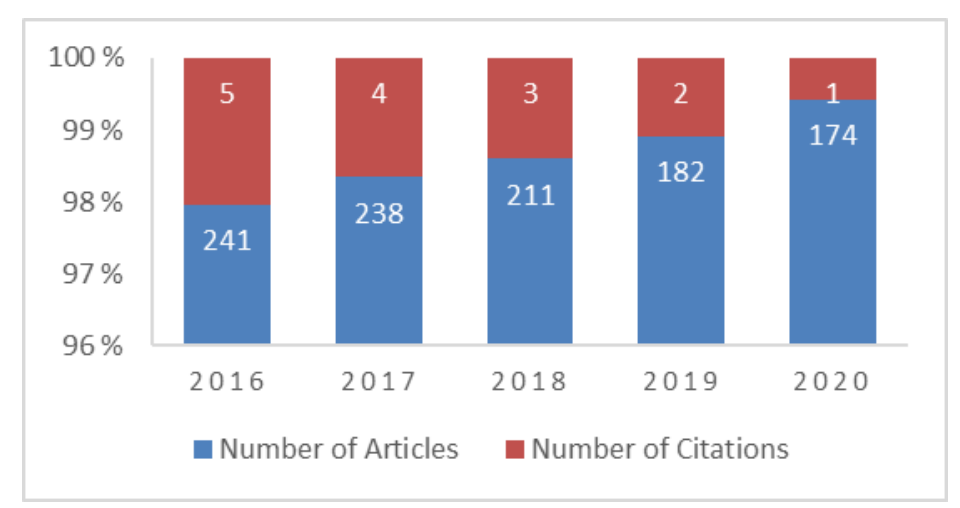

Fig. 2. Yearly Articles vs Citation

Fig. 2 shows the number of articles and citation garnered yearly from 2016 to 2010 . There is decline in article production from 2016 to 2020. Despite that MobIS is a growing trend, it is unexpected that the rate of publication will keep decreasing yearly. With this constant decline for over four years, there is possibility of further decline in coming years. It can also be seen in fig. 2 that the number of citations increase by the year the highest articles are published. This trend shows that the more articles are produced, the more they attract citations.

\subsection{MobIS Sources Citation}

Table 2. MobIS most cited sources

\begin{tabular}{ll}
\hline Sources & Citations \\
\hline Mis Quart & 1615 \\
Comput Hum Behav & 1116 \\
Inform Syst Res & 670 \\
Inform Manage-Amster & 643 \\
Decis Support Syst & 498 \\
Int J Inform Manage & 458 \\
J Marketing Res & 343 \\
Manage Sci & 328 \\
J Manage Inform Syst & 323 \\
Eur J Inform Syst & 300 \\
J Marketing & 296 \\
J Bus Res & 286 \\
Lect Notes Comput Sc & 284 \\
Comput Educ & 268
\end{tabular}




\begin{tabular}{ll} 
Internet Res & 264 \\
Int J Med Inform & 247 \\
Telemat Inform & 237 \\
J Assoc Inf Syst & 227 \\
Electron Commer R A & 224 \\
Inform Syst J & 217 \\
\hline
\end{tabular}

In table 2, the most cited sources are shown. The most cited sources are MIS Quarterly followed by Computer and human behaviour while the least in the outlet utilized by researchers that receives citations regarding MobIS is Information systems journal.

Table 3. MobIS most cited sources

\begin{tabular}{|c|c|c|c|c|}
\hline Bibliographic Source & h_index & TC & NP & PY \\
\hline International Journal of Information Management & 9 & 350 & 20 & 2016 \\
\hline Electronic Journal of Information Systems In Developing Countries & 2 & 12 & 12 & 2016 \\
\hline Jmir Mhealth And Uhealth & 5 & 51 & 12 & 2016 \\
\hline Ieee Access & 4 & 33 & 11 & 2017 \\
\hline Telematics and Informatics & 6 & 256 & 11 & 2016 \\
\hline Amcis 2017 Proceedings & 0 & 0 & 10 & 2017 \\
\hline Internet Research & 6 & 168 & 10 & 2016 \\
\hline Iet Intelligent Transport Systems & 4 & 24 & 9 & 2016 \\
\hline Information Systems Frontiers & 5 & 127 & 9 & 2017 \\
\hline International Journal of Mobile Communications & 2 & 34 & 9 & 2016 \\
\hline \multicolumn{5}{|l|}{ Centeris 2018 - International Conference on Enterprise Information Systems / Projman } \\
\hline \multicolumn{5}{|l|}{2018 - International Conference on Project Management / Hcist 2018 - International } \\
\hline Conference On Health And Social Care Information Systems And Technologies, Centeri & 2 & 12 & 7 & 2018 \\
\hline Industrial Management \& Data Systems & 3 & 97 & 7 & 2016 \\
\hline International Journal of Medical Informatics & 6 & 91 & 7 & 2016 \\
\hline Isprs International Journal of Geo-Information & 3 & 29 & 7 & 2016 \\
\hline Journal of Computer Information Systems & 2 & 27 & 7 & 2017 \\
\hline Sustainability & 2 & 15 & 7 & 2017 \\
\hline Amcis 2016 Proceedings & 0 & 0 & 6 & 2016 \\
\hline Computers in Human Behavior & 4 & 158 & 6 & 2016 \\
\hline Information Technology \& People & 4 & 37 & 6 & 2017 \\
\hline Jmir Medical Informatics & 2 & 15 & 6 & 2016 \\
\hline International Journal of Information Management & 9 & 350 & 20 & 2016 \\
\hline Electronic Journal of Information Systems In Developing Countries & 2 & 12 & 12 & 2016 \\
\hline Jmir Mhealth And Uhealth & 5 & 51 & 12 & 2016 \\
\hline
\end{tabular}


Table 3 shows MobIS bibliographic sources of articles. As shown in the table, International Journal of Information Management has the highest with the total citations of 350, the number of publications which amounts to 20 and h_index of 9 in the year 2016. Closely followed is Telematics and Informatics

\subsection{MobIS Distribution of Research Methods and Theories}

Table 4. MobIS Distribution of Research Methods

\begin{tabular}{l}
\hline Utilized Methods \\
\hline Mixed methodology \\
Quantitative methodology \\
Qualitative method \\
Geometric Constraint Model (GCM) \\
comparative analysis \\
technological approach \\
IDEF0 \\
IDEF3 \\
WFD \\
Constructive learning methods \\
Interpolation methods \\
Utilized Methods \\
Mixed methodology \\
Quantitative methodology \\
\hline
\end{tabular}

Table 4 evinces the methodological approach utilized in producing scientific articles. The research methods adopted in the publications include mixed methodology, quantitative methods, qualitative method, geometric Constraint Model (GCM), comparative analysis, technological approach, constructive learning methods, interpolation methods and IDEF0, IDEF3, WFD. Such methodologies as IDEF0, IDEF3, and WFD were implemented for business processes description.

Table 5. MobIS Distribution of Theories

\begin{tabular}{|c|c|c|}
\hline Description & & Result \\
\hline acceptance model & motivation theory & boulder model \\
\hline design theory & shafer evidence theory & conceptual-model \\
\hline innovation diffusion-theory & & confirmation model \\
\hline technology acceptance model & & dual-model \\
\hline utaut model & & effects models \\
\hline cognitive theory & & evaluation model \\
\hline
\end{tabular}


social cognitive theory

management theory

complexity theory

structuration theory

self-determination theory

protection motivation theory

prospect-theory

unified theory

\author{
expectation confirmation model \\ hegadas model \\ hierarchical model \\ hofstedes model \\ integrated model \\ mclean model \\ model development \\ new-model \\ structural equation models \\ success model \\ theoretical-model
}

The theories utilized in MobIS literatures are shown in table 5. The theories are categorized into three namely, information systems theory, psychology cognitive theory and others. According to [15], effective application of theory is critical to the development of new knowledge in information systems (IS) research. As shown in the table, psychology theories emerge in MobIS literatures. This is consistent with the study of [15] which states that IS research draws from a diverse set of disciplines, with Psychology emerging as a consistently dominant source of theories for IS.

\subsection{Authors Productivity Over Time}

Table 6. Authors production over time

\begin{tabular}{lllll}
\hline Author & Year & freq & TC & TCpY \\
\hline Defranco A & 2016 & 1 & 27 & 4.5 \\
Defranco A & 2017 & 1 & 11 & 2.2 \\
Defranco A & 2019 & 2 & 1 & 0.3 \\
Ferreira Mj & 2016 & 2 & 0 & 0.0 \\
Ferreira Mj & 2017 & 2 & 6 & 1.2 \\
Ginige A & 2017 & 1 & 4 & 0.8 \\
Ginige A & 2018 & 1 & 0 & 0.0 \\
Ginige A & 2019 & 3 & 0 & 0.0 \\
Ginige A & 2020 & 1 & 0 & 0.0 \\
Kazimierski W & 2016 & 3 & 40 & 6.7 \\
Kazimierski W & 2019 & 1 & 0 & 0.0 \\
Kim J & 2016 & 1 & 1 & 0.2 \\
Kim J & 2017 & 4 & 20 & 4.0
\end{tabular}




\begin{tabular}{lllll} 
Kim J & 2018 & 1 & 52 & 13.0 \\
Kim J & 2019 & 2 & 2 & 0.7 \\
Li Y & 2016 & 3 & 11 & 1.8 \\
Li Y & 2017 & 3 & 9 & 1.8 \\
Li Y & 2018 & 1 & 4 & 1.0 \\
Li Y & 2019 & 1 & 3 & 1.0 \\
Li Y & 2020 & 1 & 0 & 0.0 \\
\hline
\end{tabular}

Regarding authors' production over time, we investigated the top six authors and our findings showed that the majority of those top authors were already publishing articles on MobIS by the year 2016. As seen in table 5, the author Li Y. has the highest publication over time having had several articles published yearly consistently since 2016 till 2020.

Table 6. Authors production over time

\begin{tabular}{lllllll}
\hline Author & h_index & g_index & m_index & TC & NP & PY_start \\
\hline Li Y & 4 & 4 & - & 27 & 10 & 2016 \\
Zhang X & 1 & 2 & 0.17 & 8 & 8 & 2016 \\
Liu Y & 3 & 7 & 0.50 & 140 & 7 & 2016 \\
Ginige A & 1 & 2 & 0.20 & 4 & 6 & 2017 \\
Oliveira T & 4 & 6 & 0.67 & 156 & 6 & 2016 \\
Al-Emran M & 2 & 4 & - & 25 & 4 & 2018 \\
Defranco A & 2 & 4 & 0.33 & 39 & 4 & 2016 \\
Ferreira Mj & 1 & 2 & 0.17 & 6 & 4 & 2016 \\
Kazimierski W & 3 & 4 & 0.50 & 40 & 4 & 2016 \\
Kim J & 3 & 4 & 0.60 & 18 & 4 & 2017 \\
Liu J & 2 & 4 & 0.33 & 81 & 4 & 2016 \\
Moreira F & 1 & 2 & 0.17 & 6 & 4 & 2016 \\
Morosan C & 2 & 4 & 0.33 & 39 & 4 & 2016 \\
O'Connor Y & 2 & 3 & 0.33 & 13 & 4 & 2016 \\
Schmidt R & 1 & 2 & 0.25 & 6 & 4 & 2018 \\
Sharma Sk & 3 & 4 & 0.60 & 84 & 4 & 2017 \\
Wang J & 3 & 4 & 0.50 & 90 & 4 & 2016 \\
Wlodarczyk-Sielicka M & 2 & 4 & 0.33 & 30 & 4 & 2016 \\
Zhang F & 3 & 4 & 0.50 & 21 & 4 & 2016 \\
Zhang M & 2 & 4 & 0.50 & 22 & 4 & 2018 \\
\hline
\end{tabular}

*TC: total citations; NP: number of publications; PY: publication year first indexed

As shown in Table 6, among the top 20 most cited authors, only two have received $\geq 100$ citations, three have been cited $\geq 80$ times, and five have not reached 10 cita- 
tions. Overall, those authors who had the largest number of citations also had the highest h-index (i.e., h-index > 4). However, Li Y. who has been cited a total of 27 times had a h-index of 4 while Liu, Y. with 140 citations had a h-index of 3. According to [16] a bigger number of publications was an indicative of a higher author's scientific productivity as measured by the h-index and/or the g-index, but for Li Y. (hindex $=4$, g-index $=4$ ) that has the highest publications (10) and only received 27 citations so far. Considering the length of academic career, the $\mathrm{m}$-index showed that Oliveira T., (0.67), and Kim J., (0.60), Sharma Sk (0.60), were the authors who had higher growth in their scientific productivity.

\subsection{MobIS Relevant Keywords}

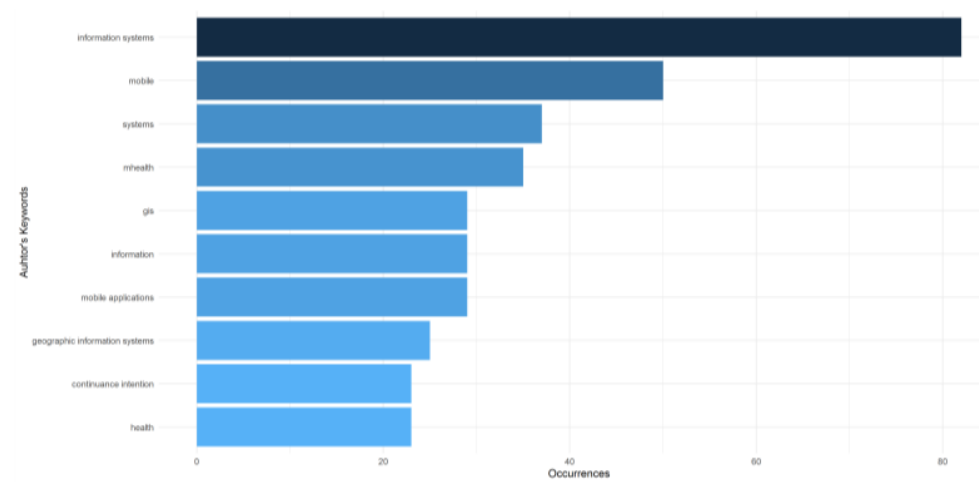

Fig. 3. Relevant Keywords

The analyses of the 10 most frequently used terms included in all the retrieved documents using the author keywords and the keyword plus terms (i.e., keywords associated to the manuscript by Thomson Reuters' Institute for Scientific Information (ISI) WOS databases) are shown in Fig. 3. A total of 3980 author keywords were retrieved. Based on the higher frequency of keywords Information systems is most used and relevant keyword followed by mobile and systems. The least amongst them is health and continuance intention.

\subsection{MobIS TCCM Analysis}

Using a simple framework of TCCM, in which T stands for theory, $\mathrm{C}$ for context, $\mathrm{C}$ for characteristics and $\mathrm{M}$ for methodology: accordingly, the following section deals with analysis of the findings in relation to theory development, context, characteristics and methodology of MobIS as revealed in the bibliometric analysis based on the data generated from WoS databases from 2016 - 2020.

Theory development ( $\mathrm{T}$ )

In this review, several theories were adopted and as expected in the realm of information systems since our focus is on mobile information systems. However, few theories utilized are from the psychology field to explain the concepts of mobIS. As revealed in Table 5, several models were also used in the mobIS research. According 
to [15], effective application of theory is critical to the development of new knowledge in information systems (IS) research. With the emergence of psychology theories in MobIS literatures, this study is consistent with [15] research which founds that IS research draws from a diverse set of disciplines, with psychology emerging as a consistently dominant source of theories for IS. New theoretical lenses that could explain uncovered areas in mobIS is needed as driving empirical studies with theories is necessary. Earlier studies suggested [17] that without a close interaction between theoretical development and empirical reality, mobIS could become merely an area of application for applied concepts from other disciplines. Arising from this, the need for new theoretical frameworks and models to explain the link among the concepts related to mobIS is recommended.

\section{Context (C)}

Research in the field of mobIS has advanced our knowledge on interaction design patterns [5], relevance for empowerment process [7] and its potential to enhance the business processes and performance. As revealed in the analysis, the context at which the mobIS research are carried out include largely Information systems, Mobile health, Mobile application, social apps. More research context is required and should also be extended to developing countries as the developed context presently dominates the research space.

\section{Characteristics $(\mathrm{C})$}

\section{Methodology (M)}

As reported in Table 4, different methodological approaches are widely used in this area of research. However, the methods used in mobIS research have become sophisticated spanning from geometric Constraint Model (GCM), comparative analysis, technological approach, constructive learning methods, interpolation methods and IDEF0, IDEF3, WFD. The challenge is to develop more mixed-method approaches when studying concepts in relation to mobIS research. To improve the methodological rigor of mobIS research, the use of more diverse analytical techniques and methods, such as content analysis, qualitative research, meta-analysis and multi-level methodologies is recommended since survey, descriptive and mixed method are mostly used in prior research in the area.

\section{$5 \quad$ MobIS Results, Discussion and Conclusion}

The current study aimed to assess the scientific literature on MobIS from 2016 - 2020. By using the TCCM framework, we were able to uncover some significant theoretical and contextual insights.

Theoretical insights

Looking from a theoretical standpoint, we observed a need for further development and use of more psychological-related theories. As noted in Figure 1, we found that there were limited psychological cognitive theories. These theories focus on human's 
ability to problem-solve, make decisions, learn, and collaborate among others [18]. Since mobIS have unique capabilities to support the ever-increasing mobile technology users and processes [19], psychological cognitive theories should be developed.

Contextual insights

Contextually, the TCCM framework shows a gap in the context already covered in the field of mobIS. So far, the contextual coverage of the literature, especially between 2016 and 2020, have already touched on some relevant research areas (as depicted in Figure 1 and Table 7) such as geographic information systems, mobile computing, service quality, mobile adoption, cloud computing and commerce. We noticed that more attention is yet to be expended on mobile-data research [20]. The rapid growth of mobIS, over the years, with it, brought opportunities and challenges of mobile data from sundry standpoints [21].

To summarise, a total of 1040 documents were produced between 2016 and 2020 considering only journal articles and conference proceedings. Out of the 1040 documents, 95 were single authored. The average authors per document was 3 and the collaboration index was 3.2. The most productive author was Kim $\mathrm{J}$ (citation: 75 , documents:8). On the average, about 3 publications were made per year and an average citations per document. The most cited source was the Mis Quarterly (1615 citations). The bibliographic source with the highest impact score was International Journal of Information Management (impact score: 9).

\subsection{Managerial implications and direction for future studies}

MobIS research and technological advancements go hand-in-hand. Thus, the persistent decline in mobIS research productivity should be addressed urgently. The cause of the decline is yet to be ascertained, at this point. We recommend that studies should be conducted to investigate this issue. Empirical work should be conducted with goals of developing cognitive theories to support mobIS. In the same vein, future researchers should also explore mobile data from various perspectives such as security, privacy, monitoring.

\subsection{Study Limitations}

One of the main limitations we experienced was our inability to extract more than 1040 documents (journal articles and conference proceedings) due to the limited timespan of four years (that is, 2016 to 2020).

\section{References}

1. Ammenwerth, E., Buchauer, A., Bludau, B., \& Haux, R.: Mobile information and communication tools in the hospital. International journal of medical informatics, 57(1), 21-40, (2000).

2. Olaleye, S. A., Oyelere, S. S., Sanusi, I. T., \& Agbo, F. J.: Experience of ubiquitous computing technology driven mobile commerce in africa: Impact of usability, privacy, trust, and reputation concern, (2018). 
3. Drew, D. A., Nguyen, L. H., Steves, C. J., Menni, C., Freydin, M., Varsavsky, T. \& Chan, A. T.: Rapid implementation of mobile technology for real-time epidemiology of COVID19. Science, 368(6497), 1362-1367 (2020).

4. Shiau, W. L., Yan, C. M., \& Lin, B. W: Exploration into the intellectual structure of mobile information systems. International Journal of Information Management, 47, 241-251 (2019).

5. da Silva, L. F., \& Freire, A. P.: An Investigation on the Use of Interaction Design Patterns in Brazilian Government Mobile Information Systems. In XVI Brazilian Symposium on Information Systems pp. 1-8 (2020).

6. Saeed, K. A., \& Xu, J. D.: Understanding diffusion of information systems-based services: evidence from mobile banking services. Internet Research, (2020).

7. Ahad, T., Busch, P., Blount, Y., \& Picoto, W.: Mobile Phone-based Information Systems for Empowerment: Opportunities for Ready-made Garment Industries. Journal of Global Information Technology Management, 1-29 (2021).

8. He, W., Nazir, S., \& Hussain, Z.: Big Data Insights and Comprehensions in Industrial Healthcare: An Overview. Mobile Information Systems, (2021).

9. Pernici, B.: Mobile information systems. Springer-Verlag Berlin Heidelberg, (2006).

10. Krogstie, J., Lyytinen, K., Opdahl, A. L., Pernici, B., Siau, K., \& Smolander, K.: Research areas and challenges for mobile information systems. International Journal of Mobile Communications, 2(3), 220-234, (2004).

11. Gebauer, J., Shaw, M. J., \& Gribbins, M. L.: Task-technology fit for mobile information systems. Journal of Information Technology, 25(3), 259-272 (2010).

12. Liu, Z., Yin, Y., Liu, W., \& Dunford, M.: Visualizing the intellectual structure and evolution of innovation systems research: a bibliometric analysis. Scientometrics, 103(1), 135$158(2015)$.

13. Olaleye, S. A.: Visualizing cultural emotional intelligence literature: A bibliometric review 2001 - 2020. In: P. Laine, I. Némethová \& T. Wiwczaroski (eds.) Intercultural competence at work. Seinäjoki: Seinäjoen ammattikorkeakoulu. Publications of Seinäjoki University of Applied Sciences B. Reports 160, 142-156 (2020).. http://urn.fi/URN:NBN:fife20201215100768.

14. Aria, M. \& Cuccurullo, C.: bibliometrix: An R-tool for comprehensive science mapping analysis, Journal of Informetrics, 11(4), pp 959-975 (2017). Elsevier, DOI: 10.1016/j.joi.2017.08.007.

15. Lim, S., Saldanha, T. J., Malladi, S., \& Melville, N. P.: Theories used in information systems research: Insights from complex network analysis. JITTA: Journal of Information Technology Theory and Application, 14(2), 5, (2013).

16. Valera-Gran, D., Prieto-Botella, D., Peral-Gómez, P., Hurtado-Pomares, M., SánchezPérez, A., \& Navarrete-Muñoz, E. M.: Bibliometric Analysis of Research on Telomere Length in Children: A Review of Scientific Literature. International Journal of Environmental Research and Public Health, 17(12), 4593 (2020).

17. Paul, J., \& Rosado-Serrano, A.: Gradual internationalization vs born-global/international new venture models: A review and research agenda. International Marketing Review, (2019).

18. Palich, L. E., \& Bagby, D. R. (1995). Using cognitive theory to explain entrepreneurial risk-taking: Challenging conventional wisdom. Journal of business venturing, 10(6), 425438.

19. Gebauer, J., Shaw, M. J., \& Gribbins, M. L. (2010). Task-technology fit for mobile information systems. Journal of Information Technology, 25(3), 259-272. 
20. Hong, S. J., Thong, J. Y., Moon, J. Y., \& Tam, K. Y. (2008). Understanding the behavior of mobile data services consumers. Information Systems Frontiers, 10(4), 431-445.

21. Laurila, J. K., Gatica-Perez, D., Aad, I., Blom, J., Bornet, O., Do, T. M. T., ... \& Miettinen, M. (2013). From big smartphone data to worldwide research: The mobile data challenge. Pervasive and Mobile Computing, 9(6), 752-771. 